Roberto Brandão Cavalcanti, Ph. D. em biologia

(McGill University, Montreal). Professor do Departamento de Biologia Animal da UnB.

\title{
Aves do cerrado
}

\section{Introdução}

Os cerrados são a forma de vegetação dominante na Região Centro-Oeste do Brasil. Para um botânico, o termo "cerrado" possui dois significados: no sentido restrito, cerrado é uma formação relativamente aberta de árvores, arbustos e gramíneas, com cobertura média do dossel de $19 \%$ e altura das árvores de 4 a 8m (Goodland, 1971); no sentido amplo, é uma paisagem contendo diversos tipos de vegetação. Assim, Eiten (1972) lista o campo limpo, campo cerrado, cerrado e cerradão, como componentes da paisagem de cerrados. As matas ciliares dos córregos e rios, embora florísticamente diferentes do cerrado - de fato, algumas são mais semeIhantes à Mata Atlântica (Rizzini, 1963) - são largamente distribuídas no Centro-Oeste e mantêm íntimo contato com o cerrado. Para estudar as aves do cerrado, é necessário reconhecer a existência destes outros habitats na região, incluindo matas secas, buritizais e brejos, e considerá-los em conjunto como membros do ecossistema de cerrados.

A composição da avifauna do cerrado certamente deve-se, em parte, a fatores históricos e parcialmente a forças que ainda hoje atuam. Várias aves do cerrado têm morfologia e hábitos semelhantes às aves de savanas da África (Fry, 1983), mas têm origens diferentes, pertencendo a grupos endêmicos dos trópicos do Novo Mundo. Suas distribuições atuais estão relacionadas aos diversos tipos de vegetação, ao ritmo sazonal de chuvas e à ação do homem, entre outros. O objetivo deste trabalho é apresentar alguns dos fatores particulares que afetam a diversidade e a distribuição das aves do cerrado.

\section{A avifauna dos cerrados}

Aproximadamente 93 familias de aves ocor- rem na América do Sul (de Schauensee, 1970). Destas, cerca de 23 surgiram na região neotropical, que engloba as américas ao sul do México, ou são a ela restritas (Mayr, citado em Welty, 1972). Nos cerrados, onde ocorrem cerca de 66 famílias (Costa et alii, 1981), encontramos vários representantes da fauna tipicamente sul-americana, como os inhambus e codornas (família Tinamidae).

São também neotropicais os beija-flores (Trochilidae), que estão ausentes da África, onde uma família de origens bastante diferentes, os Nectariniidae, apresenta forte convergência com os beija-flores na morfologia e dieta. Situação semelhante é a da ariramba, Galbula ruficauda (Galbulidae), dos cerrados e o papa-abelhas, Merops bulocki (Meropidae), das savanas africanas. Ambas são aves insetívoras com bicos longos, que comem abelhas e vespas venenosas, mas a ariramba tem maior afinidade com os tucanos, e o papa-abelhas com os martinspescadores (Fry, 1983). Os tiranídeos, que incluem o bem-te-vi, a tesourinha (figura 1), pombinha das almas e outras aves insetívoras, são de origem neotropical e aqui sofreram excepcional radiação, com mais de trezentas espécies, das quais mais de cem ocorrem nos cerrados (de Schauensee, 1970; da Costa et alii, 1981). Os tiranídeos já expandiram sua distribuição até outros continentes, tendo invadido a América do Norte. Outras famílias neotropicais bem representadas nos cerrados são os graveteiros IFurnariidae), os arapaçus (Dendrocolaptidae), as chocas (Formicariidae), os tucanos (Ramphastidae) e as arirambas (Galbulidae).

A fauna dos cerrados contém numerosos representantes de famílias do Velho Mundo, oriundas de regiões da Ásia e África. Incluem-se neste grupo os papagaios (Psittacidae), as pombas e rolas (Columbiformes), os sabiás (Turdidae) e as corujas (Stri- 


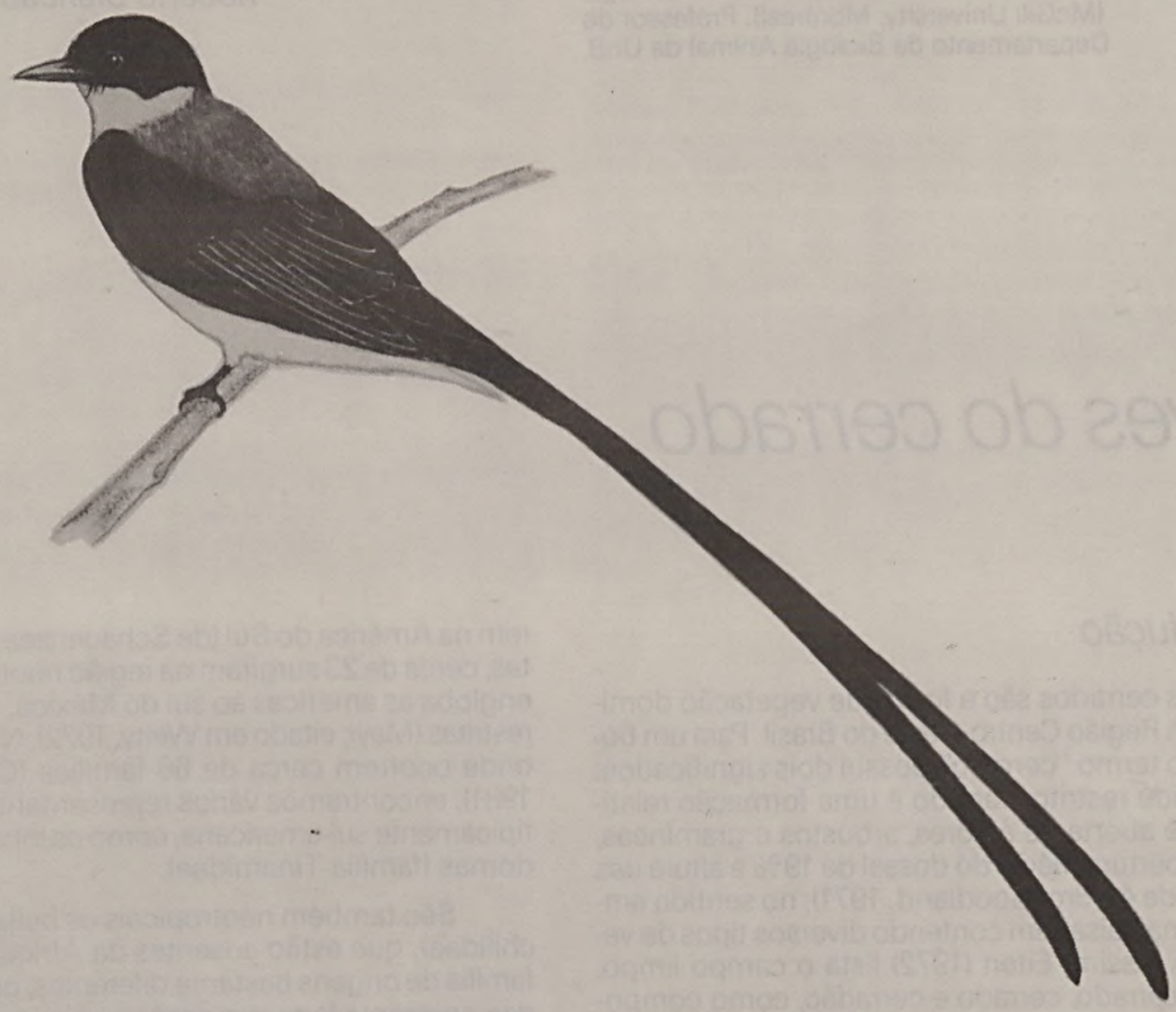

Maria Coudida Buz

Figura 1 - Tesourinha, Muscivora tyrannus, ave migratória comum no Distrito Federal nos meses de agosto e janeiro.

gidae). De origem norte-americana são possivelmente as corruíras (Troglodytidae) e os urubus (Cathartidae) (Van Tyne \& Berger, 1971).

A proporção de formas endêmicas aos cerrados e caatingas é relativamente baixa, em torno de $11 \%$ (Sick, 1965). Para esta cifra podem contribuir, em parte, a posição central e pouco isolada da Região Centro-Oeste, e em parte a diversidade de biótopos dentro dos cerrados, permitindo assim a penetração de espécies de outras regiões que aqui encontram habitats adequados. Observamos na região de Brasília aves da Região Amazônica, como o tucano, Ramphastos culminatus, nas matas ciliares. Também em Brasília existe o macuquinho, Scytalopus novacapitalis, de parentesco próximo com espécies das matas do Leste (Sick, 1965). Entre as espécies endêmicas aos cerrados, encontramos aves comuns como o batuqueiro, Saltator atricollis, e outras raramente observadas, como o macuquinho supracitado.

\section{A heterogeneidade dos habitats de cerrado}

A diversidade da avifauna, como mostram estudos realizados em várias partes das Américas, tem uma relação positiva com a complexidade do perfil da vegetação (Karr \& Roth, 1971). Os tipos de vegetação da região dos cerrados apresentam considerável variação entre si quanto ao perfil, desde campos limpos em apreciável componente vertical, passando por cerrados abertos com árvores e arbustos, até matas de copa fechada. Ė interessante verificar se a esta variação estão associadas diferenças na avifauna.

Para medir a complexidade da estrutura da vegetação, ornitólogos usam um índice proposto por MacArthur \& MacArthur (1961). Em um estudo realizado no nordeste de Mato Grosso, Fry (1970) encontrou, em geral, maior riqueza de aves nos tipos de 
vegetação de estrutura mais complexa. O habitat com maior número de espécies, 112 , foi o cerrado stricto sensu, seguido pela mata ciliar, mata mesófila, e outras formações mais abertas. Infelizmente, Fry não obteve o índice de complexidade, e não sabemos se o cerrado estudado apresentava um perfil mais complexo que o da mata, ou se a maior riqueza do cerrado deveu-se a outros fatores. Fry sugeriu que a mata, possivelmente, teria maior número de espécimes, que seria detectadas caso a amostragem fosse continuada. O método por ele utilizado, de coleta com redes ornitológicas armadas no solo, tem pouca eficiência na amostragem de aves que utilizam as árvores mais altas, comuns na mata. Na região de Brasília, Negret (1983), usando o método de amostragem visual, encontrou o maior número de espécies na mata ciliar, e as maiores populações no cerrado stricto sensu. A diversidade de espécies variou do mínimo no campo limpo ao máximo na mata ciliar, confirmando para os cerrados a relação entre diversidade de avifauna e complexidade estrutural da vegetação (Negret, 1983).

Uma característica marcante da região dos cer- rados é o contato extenso entre suas diversas formações. Nos arredores de Brasília, a disposição de matas ciliares, campos limpos, cerrados e cerradões se assemelha a um mosaico, com transições abruptas e a presença de biótopos muito diferentes a curtas distâncias um do outro (figura 2). Estas condições permitem que a avifauna de uma área restrita seja rica em aves especialistas, cada uma adaptada a um dos diversos habitats da paisagem, e ao mesmo tempo possua aves generalistas, que podem atingir os vários habitats em vôos relativamente curtos.

As aves do cerrado, em sua maioria, parecem ser especialistas na escolha de habitats. Fry (1970), entre 263 espécies, observou apenas noventa (35\%) em mais de dois habitats. Neste aspecto, os diversos biótopos representam ilhas biológicas dentro da paisagem. Se representam ilhas também quanto ao isolamento entre áreas semelhantes, não o sabemos. Aves tem alto poder de dispersão, e poderiam, por exemplo, facilmente voar de uma mata ciliar a outra separada por vários quilômetros de cerrado. Entretanto, certas aves tropicais são altamente sedentárias e têm vidas mais longas que aves de áreas tem-

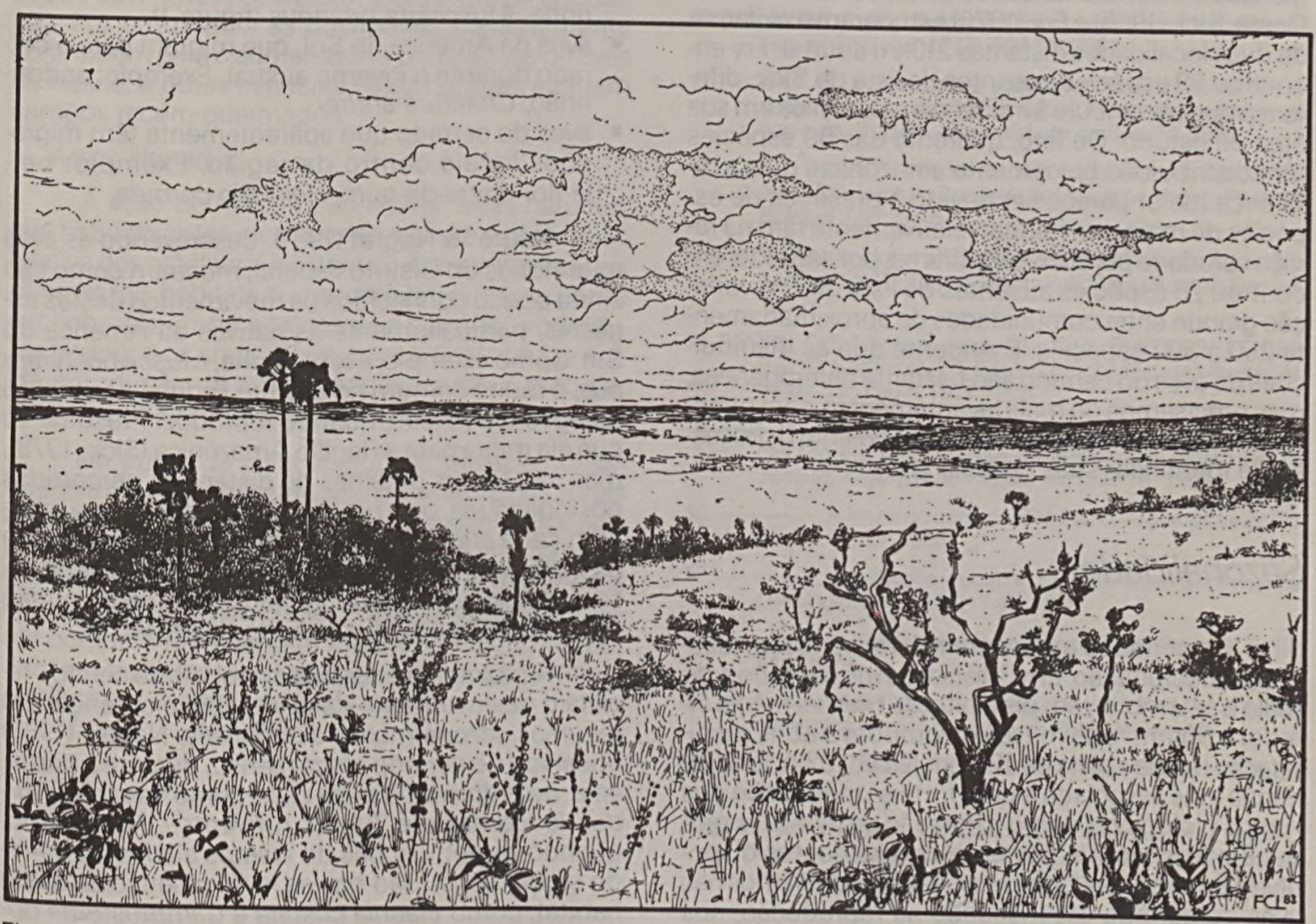

Figura 2 - Vista de um cerrado, tendo em primeiro plano um campo sujo, e em médio plano um brejo com buritis (Mauritia sp.) e uma pequena mata ciliar. 
peradas (Fry, 1983). Para determinar se o cerrado tem populações sedentárias, é necessário promover programas de anilhamento para identificação de indivíduos. Tais programas estão sendo iniciados em Brasília, por pesquisadores do centro de Estudo de Migrações de Aves do Instituto Brasileiro de Desenvolvimento Florestal - IBDF, da Universidade de Brasília - UnB e da Reserva Ecológica do Instituto Brasileiro de Geografia e Estatística - IBGE.

Nos cerrados, um mesmo tipo de habitat pode ser também variável em sua composição florística entre áreas bastante próximas. Ratter (1980), estudando duas matas ciliares na Fazenda Água Limpa da UnB, encontrou consideráveis diferenças quanto às espécies de árvores dominantes. No mesmo local, ele encontrou grandes diferenças entre cerrados stricto sensu separados por menos de $5 \mathrm{~km}$. Ao compararmos áreas assim, do mesmo habitat e, portanto, com perfil de vegetação parecido, poderíamos avaliar o efeito da composição florística na diversidade de aves, tendo eliminado a variação devido a diferenças de perfil.

A influência das regiões vizinhas dá uma dimensão adicional à variedade de espécies do CentroOeste. Sick (1955) e Fry (1970) estudaram a avifauna de duas localidades distantes $210 \mathrm{~km}$ entre si. Fry encontrou 99 espécies ausentes da lista de Sick, diferença que ele atribuiu à influência amazônica em sua área de estudo. De fato, quarenta das 99 espécies têm distribuição tipicamente amazônica, mas a diferença maior parece ser devido à presença de espécies de mata, um habitat relativamente raro na região estudada por Sick. Este último, por seu lado, encontrou 75 espécies ausentes da lista de Fry, variação grande entre comunidades de aproximadamente 250 a 300 espécies. É evidente que as distribuições de aves do cerrado são bastante heterogêneas, mas precisamos de mais levantamentos para quantificar esta heterogeneidade e levar adiante o processo de identificar suas causas.

\section{Sazonalidade}

Os cerrados apresentam forte variação sazonal de precipitação. Em Brasília, os meses secos, de maio a setembro, têm precipitaçăo mensal média inferior a $60 \mathrm{~mm}$, e os meses de outubro a abril, precipitação média acima de $120 \mathrm{~mm}$ (GDF, 1972). Esta variação está associada a uma forte sazonalidade nos ritmos biológicos, como a floração de plantas e produção de insetos e, portanto, nos alimentos disponíveis para as aves. Como resultado, observamos nas aves do cerrado sazonalidade na reprodução, nos movimentos migratórios, e no deslocamento entre habitats.
As durações dos períodos reprodutivos das aves do cerrado são pouco conhecidas, mas é na primavera que ocorre o maior número de ninhos no cerrado stricto sensu e nas áreas alteradas em Brasília (observação pessoal). Em espécies que nidificam em todos os meses do ano podem existir ritmos sazonais no número de ninhos ativos, observados na rolinha, Columbina talpacoti (Renato C. Soares, comunicação pessoal).

A reprodução na primavera, bem como a chegada no P.lanalto Central de numerosas aves migratórias, parece ter estreita correlação com a existência, neste período, de grande quantidade de insetos alados (Negret, 1983). As aves migratórias da América do Sul apresentam diversos padrões de movimento (Sick, 1968). Destes, observamos aqui os seguintes:

- aves que se reproduzem na América do Norte e Central, ocorrendo aqui no verão austral. Exemplo: maçarico, Tringa flavipes.

- aves da América do Sul, que migram para os cerrados na época da reprodução. Exemplo: tesourinha, Muscivora tyrannus (figura 1).

- aves da América do Sul, que migram para o cerrado durante o inverno austral. Exemplo: andorinhão, Chaetura andrei.

- aves do cerrado que aparentemente têm migrações locais dentro da região. Exemplo: beija-flor-chifre-de-ouro, Heliactin cornuta.

Negret \& Negret (1981), descrevendo as aves migratórias do Distrito Federal, mostram como são ainda pouco conhecidos os movimentos destas espécies, particularmente as nativas da América do Sul. Como exemplo, a tesourinha, Muscivora tyrannus, é muito comum no Distrito Federal nos meses de agosto a janeiro, quando reproduz. Presume-se que ela migra para a Região Amazônica (Sick, 1979), mas não temos detalhes de distâncias percorridas por indivíduos, ou a proporção de adultos que retornam cada ano. Da mesma forma, não sabemos se os movimentos de aves dentro dos cerrados representam migrações para lugares determinados ou são movimentos nomádicos ou de dispersão.

A proximidade entre os habitats do cerrado facilita o deslocamento das aves para a obtenção de recursos sazonalmente disponíveis. Negret (1983) observou no cerrado stricto sensu, durante a primavera, aves típicas da mata ciliar, como os sabiás, Turdus leucomelas e Turdus rufiventris. No inverno, quando as populações de insetos alados no cerrado stricto sensu são baixas, aves insetívoras deste habitat, como Elaenia cristata e Camptostoma obsoletum foram observadas na mata ciliar (Negret, 1983). 


\section{Efeitos do homem}

\section{- Fogo}

As características xeromórficas do cerrado, conferindo às árvores e arbustos resistência ao fogo, e a ocorrência freqüente de vastas queimadas durante a estação seca, têm levado a considerável debate sobre a importância do fogo na fisionomia dos cerrados. Embora reconhecendo que o fogo tende a estimular formações mais abertas (Eiten, 1972), autores recentes atribuem a estrutura dos cerrados aos nutrientes do solo, relevo e umidade (Eiten, 1972; Goodland \& Ferri, 1979).

À falta de estudos sobre a ação do fogo na avifauna, podemos apenas indicar possíveis efeitos. As taxas de mortalidade podem subir por várias razões. Aves de rapina são atraídas às queimadas, onde apanhim animais cansados pela fuga e intoxicados pela fumaça. Para os que sobrevivem inicialmente, o deslocamento da residência normal e falta de alimento e cobertura vegetal na área queimada podem reduzir a sobrevivência futura. Para aves que se reproduzem durante a estação seca, a perda sistemática de ovos e de filhotes pode afetar a estrutura da população. Por outro lado, as queimadas possivelmente contribuem para o aumento das populações de aves de rapina, e outas espécies cujos habitats incluem campos recém-queimados.

\section{- Areas alteradas}

A ação do homem, ao alterar áreas naturais, cria habitats antes inexistentes e altera a proporção relativa dos habitats já existentes. As aves nativas que utilizam tais habitats aumentam em número, como a rolinha, Columbina talpacoti; a corruira, Troglodytes aedon, e os anus, Guira guira e Crotophaga ani. Há introdução de aves exóticas, como o bico-delacre, Estrilda astrild, e o pardal, Passer domesticus.

Do ponto de vista ecológico, talvez a conseqüência mais interessante seja o aumento nas zonas de contato entre espécies de habitats diferentes. Nos pomares, encontram-se aves de cerrado e das matas ciliares, como a corruíra-da-mata, Thryothorus leucotis, e o sabiá-do-campo, Mimus saturninus. Estes contatos representam experimentos, onde podem ser testadas teorias sobre competição interespecífica e a escolha de habitats.

\section{Bibliografia}

1. DA COSTA, Cláudia C et alii. Fauna do cerrado. Instituto Brasileiro de Geografia e Estatística, 1981.

2. DE SHCAUENSEE, R.M. A guide to the birds of South America. Edinburgh, Oliver and Boyd, 1970.

3. EITEN, G. The cerrado vegetation of Brazil. Botanical Review, 38 (2): 201-341, 1972.

4. FRY, C. H. Ecological distribution of birds in North-Eastern Mato Grosso State, Brazil. Anais da Academia Brasileira de Ciências, 42 (2): 275-318, 1970

5. Birds in savana ecosystems. In: BOURLIÉRE, F. ed Tropical savanas. Amsterdam, Elsevier, 1983

6. GOODLAND, R. A phsiognomic analysis of the 'cerrado' vegetation of Central do Brasil. Journal of Ecology, 59:411-19, 1971.

7. \& FERRI, M. G. Ecologia do cerrado. São Paulo, Ed da Universidade de São Pauldltatiaia, 1979.

8. GOVERNO DO DISTRITO FEDERAL. Inventário florestal do Distrito Federal. Brasilia, GDF/Secretaria de Agricultura e Produção, 1972

9. KARR, J. R. \& ROTH, R. R. Vegetation structure and avian diversith in several New World areas. American Naturalist, 105: 423-36, 1971.

10. MacARTHUR, R. H. \& MacARTHUR, J. W. On bird species diversity. Ecology, 42 (3): 594-98, 1961

11. NEGRET, A. J. Diversidade e abundância da avifauna na Reserva Ecológica do IBGE-Brasilia/DF; tese de mestrado em ecologia. Brasília, Universidade de Brasilia, 1983.

12. \& NEGRET, R. M. As aves migratórias do Distrito Federal. S. 1. Instituto Brasileiro de Desenvolvimento Florestal. Boletim Técnico, 6 .

13. RATTER, J. A. Notes on the vegetation of Fazenda Agua Lim. pa (Brasília, DF, Brasil). Edinburgh, Royal Botanic Garden. 1980

14. RIZZINI, C. T. A flora do cerrado. In: SIMPOSIO SOBRE O CERRADO. São Paulo, Ed. Edgard Blucher/Ed. da Universida. de de São Paulo, 1971

15. SICK, H. O aspecto fitofisionômico da paisagem do médio Rio das Mortes, Mato Grosso, e a avifauna da região. Rio de Janeiro, Arquivos do Museu, 42: 541-76, 1955

16. A fauna do cerrado. São Paulo, Arquivos de Zoolo. gia, 12: 71-93, 1965

17. Vogelwanderugen in Kontinentalen Sudamerika Die Vogelwatte, 24: 217-43, 1968

18. Migrações de aves no Brasil. Brasil Florestal, 9 (39): 7.10, 1979

19. VAN TYNE, J. \& BERGER, A. J. Fundamentals of ornithology. New York. Dover Publications, 1971

20. WELTY, J. C. The life of birds. 2 ed. Philadelphia, W. B. Saunders, 1975

Nota: O autor agradece a Maria Cândida V. Cruz e a Fernando C. Lopes a execução das gravuras, e a Alvaro Negret a crítica do texto. 


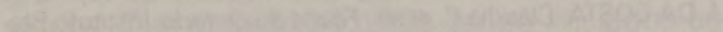

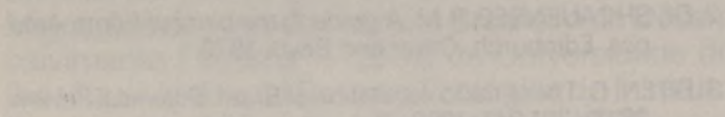

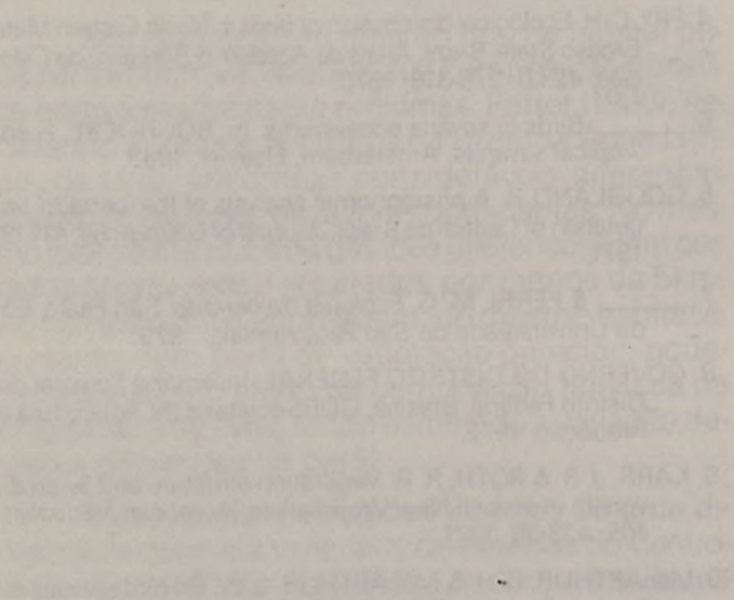

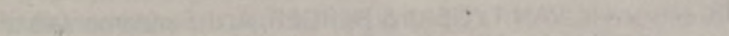

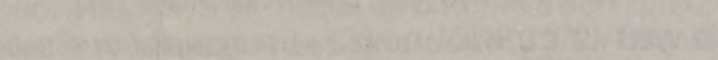

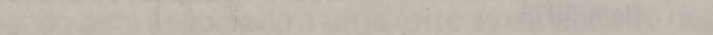

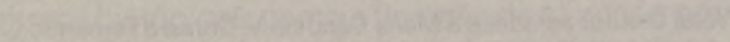

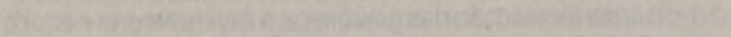

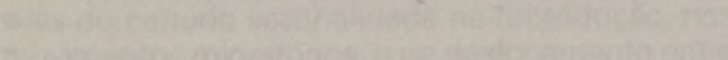
(1)

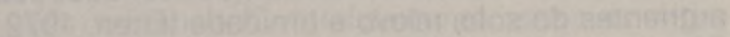

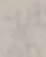

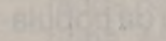

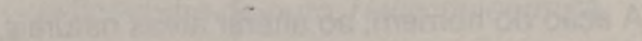

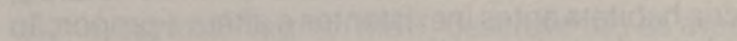

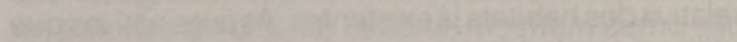

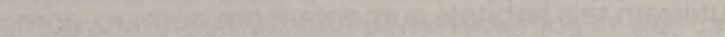

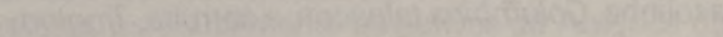

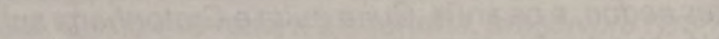

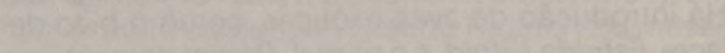

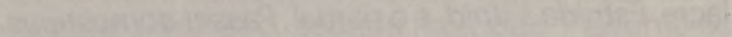

